\title{
Nauji vaistai tuberkuliozei gydyti
}

\author{
Greta Musteikienè \\ LSMU MA Pulmonologijos klinika
}

Reikšminiai žodžiai: daugeliui vaistų atspari tuberkuliozė, bedakvilinas, delamanidas, klofaziminas, linezolidas.

Santrauka. Nors naujų tuberkuliozės atvejų Lietuvoje kasmet mažeja, atsparios vaistams tuberkuliozės atvejų skaičius išlieka nepriimtinai didelis. Pastaraisiais metais daugeliui vaistų atsparios tuberkuliozės vaistų sąrašas pasipildè naujais vaistais, kurie ir yra apžvelgiami šiame straipsnyje.

Daugeliui vaistu atspari tuberkuliozè (DVA-TB, angl. multidrug-resistant TB, MDR-TB) - tai liga, sukelta tuberkuliozès (TB) mikobakterijuc, atsparių bent dviem pagrindiniams vaistams nuo TB: rifampicinui ir izoniazidui. Nors Lietuvoje naujų TB atvejų skaičius kasmet mažèja [1], DVA-TB dalis tarp jų išlieka didelè. 2015 metais DVA-TB Lietuvoje sudarẻ 11,5 proc. iš visų naujų TB atvejų [1], tuo tarpu bendrai pasaulyje, remiantis Pasaulio sveikatos organizacijos (PSO) duomenimis, DVA-TB sudaro apie 3,5 proc. iš visų naujų atvejų [2]. Dèl šios priežasties PSO priskiria Lietuvą didelio sergamumo DVA-TB šalims, o 2014 metais čia nustatytas ir didžiausias Europos regione ypač vaistams atsparios tuberkuliozès (YVA-TB (atsparios bent rifampicinui, izoniazidui, bent vienam aminoglikozidui ir fluorochinolonui (angl. extensively drug-resistant TB, XDR-TB)) paplitimas tarp DVA-TB atvejų (24,7 proc.) [3]. Nustačius atsparumą daugeliui vaistų, sudaryti efektyvų gydymo režimą esti ypač sudètinga.

TB gydyti vartojama daugiau nei dvidešimt vaistų, tačiau dauguma atrasti jau prieš kelias dešimtis metų, kai kurių iš jų efektyvumas nedidelis, o šalutinis poveikis ženklus.

Pastaruoju metu atsirado keletas naujų vaistų. Iš jų du - nauji DVA-TB gydyti registruoti preparatai, ir du - anksčiau vartoti kitu infekcijų gydymui, kurie, nors iki šiol neturi patvirtintos indikacijos vaisto apraše, PSO rekomendacijose jau yra siūlomi DVA-TB gydymui.

Nuo 2015 gruodžio 31 dienos trys iš šių keturių medikamentų jau gali būti skiriami ir Lietuvos DVA-TB pacientams (bedakvilinas (BDQ), delamanidas (DEL) ir linezolidas (LZD)). Šiu vaistų skyrimas, remiantis Lietuvos Respublikos sveikatos apsaugos ministro ìsakymu, turi būti užtikrintas šešiasdešimčiai pacientų per metus. Šie vaistai gali būti skiriami septyniose ịsakyme numatytose Lietuvos ligoninèse, pritarus gydytojų konsiliumui, pacientams nepažeidžiantiems gydymo režimo. BDQ, DEL ir LZD neskiriami jaunesniems nei 18 metų ir vyresniems nei 65 metu asmenims bei infekuotiems ŽIV asmenims. BDQ negali būti skiriamas kartu su DEL. Šie vaistai skiriami ne ilgesniam kaip 6 mėnesių gydymo režimui. LZD gali būti skiriamas kartu su BDQ ar DEL, gydymo šiuo vaistu trukmè - iki 18 mènesių.

\section{DAUGELIUI VAISTŲ ATSPARIOS TUBERKULIOZĖS GYDYMO SCHEMOS}

DVA-TB gydymo režimas sudaromas pagal esamą TB sukèlèjo jautrumą vaistams bei vaistų nuo TB efektyvumą. Šiais metais, atsižvelgdama i naujus įvairių atliktų tyrimų rezultatus, PSO pakeitė iki šiol galiojusias DVA-TB gydymo rekomendacijas [4].

Pagal dabartines rekomendacijas sergantiems DVA-TB pacientams intensyvios gydymo fazès metu skiriami penki vaistai (lentelè) - mažiausiai 4 tikètinai efektyvūs antros eilès vaistai nuo TB (vienas iš A grupès, vienas iš $B$ grupès, bent du iš $C$ grupès) bei pirazinamidas. D grupès vaistų tikslinga skirti, jei nesusidaro penkių efektyvių vaistų derinys [4]. Rekomenduojama intensyvios gydymo fazès trukmè yra 6-8 mènesiai. Tęsimo fazès metu skiriami bent 3 efektyvūs antros eilès vaistai nuo TB.

Bendra DVA-TB gydymo trukmè - 18-24 mènesiai. Ji gali kisti priklausomai nuo bakteriologinių tyrimų rezultatų ir kitų gydymo efektyvumo požymių.

PSO taip pat siūlo ir trumpesni gydymo kursą, kurio trukmè 9-12 mènesių. Jo metu 4-6 mènesius skiriami šie vaistai: fluorochinolonas (A grupè), leidžiamas vaistas iš B grupès, etionamidas, CFZ, pirazinamidas, etambutolis ir didelès izoniazido dozès. Po to tęsimo fazèje dar 5 mènesius skiriami fluorochinolonas, CFZ, pirazinamidas ir etambutolis. Šis gydymo režimas galimas tik ligoniams, kurie anksčiau nebuvo gydyti antros eilès vaistais nuo TB, kuriems yra patvirtintas TB sukèlejo jautrumas fluorochinolonams ir antros eilès leidžiamiesiems vaistams. 


\section{BEDAKVILINAS}

Bedakvilinas (BDQ) - tai pirmas naujas vaistas TB gydyti per beveik penkiasdešimt metų. 2012 metais šis vaistas patvirtintas JAV Maisto ir vaistu tarnybos, 2013 metais Europos vaistų agentūros, kaip medikamentas DVA-TB gydymui. PSO 2013 metais rekomendavo BDQ DVA-TB gydymui, su sąlyga, kad vaistas bus skiriamas atsakingai parenkant pacientus, juos aktyviai stebint, skiriant vaistą gydymo schemoje su kitais vaistais nuo TB, skiriamais pagal PSO principus [5].

BDQ veikia užblokuodamas mikobakterijų ATP sintazę - membranoje esantị baltymą, atsakingą už energijos gamybą ir viduląstelinị metabolizmą [6], taip sunaikindamas ne tik aktyviai besidalijančias, bet ir tuo metu neaktyvias TB mikobakterijas. Toks vaisto veikimo mechanizmas yra naujas tarp vaistų nuo TB, tačiau yra duomenų, kad jis turi kryžmini rezistentiškumą su CFZ [7]. BDQ (arba DEL) taip pat įeina ì rekomenduojamą YVA-TB pagrindinių vaistų schemą, kartu su LZD, CFZ ir pirazinamidu [7]. Pirazinamidas siūlomas dèl galimo sinerginio veikimo su BDQ, net ir tais atvejais, kai pirazinamidui yra fenotipinis atsparumas.

BDQ efektyvumas yra pademonstruotas IIB fazès klinikiniame tyrime (TMC207-C208), kuriame pacientai buvo gydomi pagal PSO rekomenduojamą gydymo režimą kartu su placebu arba BDQ. Buvo nustatyta, kad po 120 savaičių pacientams, gavusiems BDQ, dažniau ìvyko skreplių kultūros konversija, palyginti su kontroline grupe. Taip pat didesnis skaičius pacientu pasveiko: po 120 savaičių - 57,6 proc. pacientų, gydytų BDQ, ir 31,8 proc. gydytu kitoje grupejje $(p=0,003)$ [8]. Vaistas buvo gana gerai toleruojamas, nors, lyginant su placebo grupe, dažniau pasireiškẻ kepenų funkcijos rodiklių pakitimai, taip pat BDQ buvo susietas su QTc prailgejjimu. Dèl šios priežasties gydant šiuo vaistu rekomenduojama reguliariai matuoti QTc intervalą. Perspèjama BDQ atsargiai skirti infekuotiems ŽIV pacientams dẻl sąveikos su antiretrovirusiniais vaistais, gausiai vartojantiems alkoholị, esant gretutinèms ligoms (pavyzdžiui, sergant cukriniu diabetu). Nerekomenduojama skirti kartu su DEL. Kaip ir kituc vaistų atveju, BDQ neturètų būti vienintelis vaistas, kuris pridedamas, kai nustatoma, kad esamas TB gydymo režimas neefektyvus [5].

Vaistas gaminamas $100 \mathrm{mg}$ tabletėmis, kurių galiojimo laikas yra 2 metai. Pirmas 14 dienų vaisto turi būti skiriama po $400 \mathrm{mg}$, kaip ìsotinamoji dozè, vèliau dozé mažinama iki $200 \mathrm{mg}$ tris kartus per savaitę dar 22 savaites. BDQ pusinès eliminacijos laikas ilgas - apie 5,5 mènesio.

\section{DELAMANIDAS}

Delamanidas (DEL) - dar vienas naujas vaistas, turintis formalią DVA-TB gydymo indikaciją. Jị 2013 metais patvirtino Europos vaistų agentūra, o 2014 metais - Japonijos vaistų ir medicininès paskirties priemonių agentūra. PSO rekomendacijose šis vaistas rekomenduojamas
Lentelè. Vaistai, skiriami DVA-TB gydyti

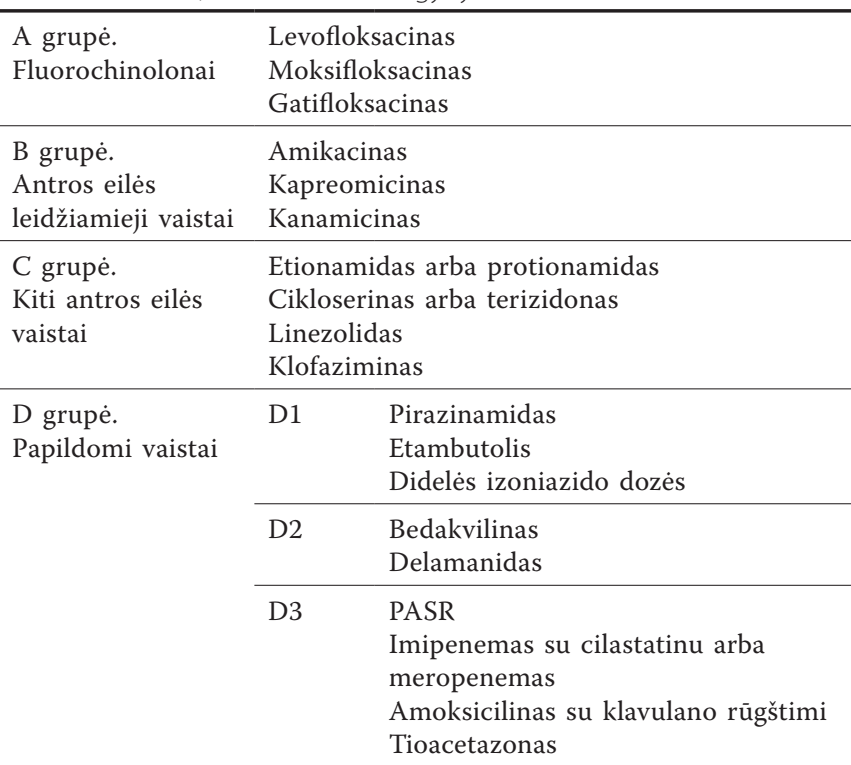

WHO treatment guidelines for drug-resistant tuberculosis 2016 update. WHO, Geneva. 2016.

DVA-TB pacientų gydymui kaip papildomas vaistas, jei yra skiriamas optimaliomis sąlygomis, kas apima atsakingą pacientų parinkimą, aktyvų jų stebejjimą, vaisto vartojimą kartu su kitais vaistais, kurie skiriami pagal PSO principus [9]. Kaip ir gaudamas BDQ, prieš pradėdamas vartoti DEL pacientas turi pasirašyti informuoto sutikimo formą.

DEL slopina mikobakterijos ląstelès sienelès sintezę. Šio vaisto veiksmingumas buvo tirtas IIB fazès tyrime, kurio metu skreplių kultūros konversija vertinta po 8 savaičių: geresni konversijos rodikliai nustatyti toje pacientų grupejje, kuri šalia bazinių vaistų gavo DEL, lyginant su placebo grupe. III fazès klinikinio tyrimo rezultatuc tikimasi sulaukti 2017 metais.

Šiuo metu sukaupti saugumo duomenys leidžia manyti, kad vaistas toleruojamas gerai, o pagrindinis nepageidaujamas poveikis yra vidutinis QTc prailgejjimas be klinikinès išraiškos, kaip ir BDQ atveju. Atkreiptinas dėmesys $\mathfrak{i}$ tai, kad vaisto metabolizme dalyvauja albuminas, dèl to daugiau nepageidaujamų poveikių stebima pacientams, kuriems nustatoma hipoalbuminemija.

DEL skiriamas $100 \mathrm{mg}$ du kartus per parą 24 savaites. Vaistas tiekiamas $50 \mathrm{mg}$ tabletėmis, jo galiojimo laikas 4 metai. Pusinès eliminacijos laikas yra 38 valandos. DEL taip pat laikomas saugiu skiriant vaikams nuo 13 metu, tačiau trūksta saugumo duomenų skiriant vaistą jaunesniems vaikams, senyviems asmenims ar néščiosioms ir krūtimi maitinančioms moterims.

\section{LINEZOLIDAS}

Linezolidas (LZD) yra oksazolidinoninis antibiotikas, kuris yra patvirtintas gramteigiamoms infekcijoms gydyti, tačiau jau kurị laiką yra skiriamas ir DVA-TB gydyti be formalios indikacijos. Daugelio kohortu stebèjimas parodè, kad LZD gali buti efektyvus labai atsparių TB formuc 
gydymui [7]. LZD saugumo ir veiksmingumo duomenys surinkti daugiausia iš kohortinių tyrimų bei vieno atsitiktinès atrankos tyrimo, kuriame tirtas 41 Pietų Korejos pacientas, sergantis YVA-TB, gydytas specifiniu atsparios TB gydymo režimu ir LZD [7]. LZD buvo pradètas vartoti tuoj pat (pirma grupè) arba po 2 mėnesių gydymo (antra grupè). Šio tyrimo duomenimis, pacientų, kuriems LZD buvo skirtas anksčiau, kultūrų konversija įvyko greičiau: praejus 4 ménesiams po atsitiktinès atrankos, pirmoje grupejje skreplių kultūros konversija buvo nustatyta 79 proc. pacientuc, o antroje - 35 proc. [10]. Vaistas turi daug nepageidaujamų poveikių, ypač jei skiriama daugiau nei $600 \mathrm{mg}$ per parą [11]. Skiriant šias dozes, Sotgiu ir bendr. atliktos metaanalizès duomenimis, nepageidaujami poveikiai buvo stebèti 58,9 proc. pacientų: iš jų 68,4 proc. atvejų nepageidaujamas poveikis buvo vertintas kaip sunkus ir pasireiškè anemija (38,1 proc.), periferine neuropatija (47,1 proc.), virškinimo traukto sutrikimais (16,7 proc.), optiniu neuritu (13,2 proc.) ir trombocitopenija (11,8 proc.) [11]. Panašu, kad nepageidaujami poveikiai priklauso nuo vaisto susikaupimo organizme ir vaisto dozès [7]. Skiriant LZD senyviems asmenims, taip pat padideja periferinių neuropatijų ir kaulų čiulpų slopinimo atvejų dažnis. Šiuo metu vykdomi klinikiniai tyrimai, bandantys nustatyti optimalų LZD dozavimą, i̇skaitant vaisto skyrimą kas antrą parą. Kol kas vaistą siūloma skirti po 600 mg per parą, dozę sumažinant iki $300 \mathrm{mg}$, jei pasireiškia vaisto toksiškumas.

Vaistas tiekiamas $600 \mathrm{mg}$ tabletėmis, kurių galiojimo laikas yra 3 metai. Pusinès eliminacijos laikas - 5-7 valandos. Vaistą galima saugiai skirti vaikams, nėščiosioms ar krūtimi maitinančioms moterims.

\section{KLOFAZIMINAS}

Klofaziminas (CFZ) yra vaistas, kuris, kaip ir LZD, neturi formalios indikacijos DVA-TB gydymui, tačiau yra rekomenduojamas PSO kaip vienas iš bazinių vaistų sudarant DVA-TB gydymo schemą. CFZ iki šiol vartotas ilgą laiką kaip vaistas nuo raupsų. Dèl savo veikimo prieš mikobakterijas taip pat buvo išbandytas gydant DVA-TB, ittraukus i devynių mėnesių gydymo režimą, kitaip vadinamą Bangladešo režimu, pagal kurị vẻliau sudarytas PSO rekomenduojamas trumpesnis DVA-TB gydymo režimas.

Vaisto veikimo mechanizmas iki šiol nèra iki galo aiškus, tačiau žinoma, kad galimas kryžminis atsparumas su BDQ.

CFZ saugumo ir veiksmingumo duomenys surinkti iš stebejjimo tyrimų duomenų ir iš neseniai Kinijoje atlikto atviro atsitiktinès atrankos tyrimo [12]. Šio tyrimo metu 105 pacientai buvo atsitiktinai atrinkti i dvi grupes skiriant DVA-TB gydymo režimą su arba be CFZ 100 mg per parą. Skreplių kultūros konversija buvo ankstyvesnè CFZ grupéje, palyginti su kontroline, gydymas taip pat dažniau buvo sėkmingas CFZ grupėje (73,6 proc. atvejų, lyginant su 53,8 proc. CFZ negavusių grupeje $(p=0,035))[12]$. Šiuo metu vaistas yra tiriamas III fazès tyrime (STREAM tyrimas) kaip sutrumpinto (9 ménesiu trukmès) DVA-TB gydymo režimo dalis.

Ryškiausi CFZ sukeliami nepageidaujami poveikiai yra odos pigmentacijos pokyčiai, kurie varijuoja nuo oranžinès spalvos iki tamsiai juodai violetinès. Taip pat gali sukelti pilvo skausmus. Kaip ir DEL bei BDQ, CFZ siejamas ir su QTc prailgèjimu.

CFZ tiekiamas $100 \mathrm{mg}$ tabletėmis, iprastinè dozė yra 100-200 mg per parą priklausomai nuo svorio visą gydymo kursą. Vaisto galiojimo laikas 5 metai. Vaisto pusinès eliminacijos laikas yra 70 dienų. Vaistą saugu skirti su visais antiretrovirusiniais vaistais.

\section{NEW DRUGS IN THE TREATMENT OF TUBERCULOSIS}

\section{GRETA MUSTEIKIENE \\ DEPARTMENT OF PULMONOLOGY ACADEMY OF MEDICINE LUHS}

Keywords: multidrug-resistant tuberculosis, bedaquiline, delamanid, clofazimine, linezolid.

Summary. Despite the fact, that the incidence of tuberculosis in Lithuania is decreasing, incidence of multidrug-resistant tuberculosis remains unacceptably high. In recent years, there were new developments in the field of multidrug-resistant tuberculosis, including the apearance of new drugs, which are reviewed in this article.

\section{LITERATŪRA}

1. Lietuvos tuberkuliozès registras, 2015.

2. Drug- resistant TB surveillance and response supplement Global tuberculosis report 2014. World Health Organisation.

3. Acosta C BJ de CP et al. Tuberculosis surveillance and monitoring in Europe 2015, vol. 1, European Centre for Disease Prevention and Control/WHO Regional Office for Europe, 2015

4. WHO treatment guidelines for drug-resistant tuberculosis 2016 update. WHO, Geneva. 2016.

5. The use of bedaquiline in the treatment of multidrug-resistant tuberculosis: interim policy guidance. World Health Organization; 2013.

6. Andries $K$, Verhasselt $P$, Guillemont $J$ et al. A diarylquinoline drug active on the ATP synthase of Mycobacterium tuberculosis. Science. American Association for the Advancement of Science; 2005;307(5707):223-7.

7. The SWIFT Response Project handbook "Treatment of Drug-Resistant TB with New and Repurposed Medications: A Field Guide for Optimal Use ". Second Edition: March 2016

8. Diacon AH, Pym A, Grobusch MP et al. Multidrug-resistant tuberculosis and culture conversion with bedaquiline. New England Journal of Medicine. Mass Medical Soc; 2014;371(8):723-32.

9. The use of delamanid in the treatment of multidrug-resistant tuberculosis: interim policy guidance. World Health Organization; 2014.

10. Lee M, Lee J, Carroll MW et al. Linezolid for treatment of chronic extensively drug-resistant tuberculosis. New England Journal of Medicine. Mass Medical Soc; $2012 ; 367(16): 1508-18$.

11. Sotgiu G, Centis R, D'Ambrosio L et al. Efficacy, safety and tolerability of linezolid containing regimens in treating MDR-TB and XDR-TB: systematic review and meta-analysis. European Respiratory Journal. Eur Respiratory Soc; 2012;40(6):1430-42.

12. Tang $\mathrm{S}$, Yao $\mathrm{L}, \mathrm{Hao} X$ et al. Clofazimine for the treatment of multidrug resistant tuberculosis: prospective, multicenter, randomized controlled study in China. Clinical Infectious Diseases. Oxford University Press; 2015;60(9):1361-7. 